\title{
Biospheric Evolution
}

\section{Is Coarsely Deterministic}

David Schwartzman

Department of Biology, Howard University

Correspondence | David Schwartzman, dschwartzman@gmail.com

Citation | Schwartzman, David. 2020. "Biospheric Evolution Is Coarsely Deterministic.” Journal of Big History IV (2): $60-66$.

DOI | https://doi.org/10.22339/jbh.v4i2.4230

\begin{abstract}
Starting with the origin of life, I argue that the general pattern of the tightly coupled evolution of biota and climate on Earth has been the very probable outcome from a relatively small number of possible histories at the macroscale, given the same initial conditions. Thus, the evolution of the biosphere self-selects a pattern of biotic evolution that is coarsely deterministic, with critical constraints likely including surface temperature as well as oxygen and carbon dioxide levels in the atmosphere. Environmental physics and chemistry drive the major events in biotic evolution, including photosynthesis and oxygenic photosynthesis, the emergence of new cell types (eucaryotes) from the merging of complementary metabolisms and finally multicellularity and even encephalization.
\end{abstract}

\section{Revival of an Old Debate: "Playing the Tape Again," Contingency vs Predictability in Evolution}

Here I revisit a provocation: that the evolution of the biota, embedded in the biosphere, has been coarsely deterministic (Schwartzman 1999, 2002;

Schwartzman 2001; Lineweaver and Schwartzman 2004; Schwartzman and Lineweaver 2005). I obviously take sides in an old but still active debate. If the "tape were played again," would the outcome be roughly the same, or is biologic evolution non-repeatable given similar initial conditions and roughly similar solar/planetary/impact history? Stephen J. Gould in his exchange with Simon Conway Morris (Conway Morris and Gould 1998-1999) took the position that the origin of life is very probable, but biologic evolution is not predictable, while Conway Morris argued that the evolution of life is predictable, but the origin of life was an unlikely event.
I agree in part with both scientists on the side of coarse determinism, both are very probable given the Earth/Sun's initial conditions. Conway Morris's position is largely based on his case for strong convergence of morphologies and biochemistries in the history of life (Conway Morris 2003; 2010; 2015). The issue of contingency versus determinism in this history continues to be a focus of vigorous research (e.g., Blount 2017; Blount et al. 2018; Simoes 2019). Determinism almost certainly breaks down at finer levels; it is hard to imagine that giraffes and blue whales are on Earth-like planets around Sun-like stars in our galaxy, except in bad science fiction novels!

\section{Cosmic Thermobiology, Emergence} at the Edge of Stability

Returning to the likelihood of the origin of life on Earth, we can start with the observation that the cooling of the Earth and its climate and growing com- plexity of lifeforms are correlated, consistent with the same trend for complexity in the universe since the Big Bang (Lineweaver and Schwartzman 2004; Chaisson 2009). A roughly deterministic cosmic thermobiology can be inferred from the evolution of life on Earth, enabling us to predict a potential similar pattern of growing complexity in biologic evolution on the surfaces of terrestrial planets around Sun-like stars. Of course, this pattern, indeed abiogenesis itself, is contingent on the context of the planetary system, i.e., stellar mass/luminosity history, distance of the terrestrial planet to its host star, and the initial conditions and impact history of the planet considered (see chapter 10, Schwartzman 1999 2002).

Starting with The Last Universal Common of Life (LUCA), I argue that the emergence of the main groups of living organisms occurred at their edge of 
stability, at their upper temperature limits. LUCA emerged at thermophilic to hyperthermophilic temperatures in submarine alkaline hydrothermal vents (Martin and Russell 2007; Lane 2015; Weiss et al. 2016a; Sojo et al. 2016). This scenario is robustly supported, e.g., by the stereochemistry of FeS clusters in the cores of primitive enzymes such as ferredoxin, inferred to have been inherited from sulfide minerals deposited in the vents (Russell and Hall 1997) and the key role of iron catalysis and iron sulfide minerals in the origin of life (Camprubi et al. 2017; Li et al. 2018).

A critical driver of determinism in evolutionary history has been the strong coupling of biologic evolution with climate history as a result of the long-term biogeochemical carbon cycle. A key process in this cycle is the progressive increase of the biotic enhancement of weathering resulting from the increase of terrestrial productivity and evolution of the land biota in the history of life (Schwartzman 1999, 2002; 2015). In the case of the Earth, the trend to present of decreasing volcanic outgassing, increasing continental area and biotic enhancement of weathering has outweighed the warming influence of rising solar luminosity, but the latter will overwhelm cooling influences in the future (e.g., Caldeira and Kasting 1992). Further, considering the astrobiological implications, if biospheres emerge in a strongly habitable context, their survival is likely enhanced by analogous strong coevolutionary mechanisms (Nicholson et al. 2018; Lenton et al. 2018).

The following is a test of the difficulty for steps in major evolutionary emergences: If a potential constraint is released at the time of emergence, then it was virtually inevitable ("easy"). The upper temperature limits of growth of the main groups of living organisms corresponds to the approximate climatic temperature at the times of their first emergence, assuming a very warm Archean climate (Schwartzman 1999, 2002; Schwartzman and Knauth 2009; Garcia et al. 2017; Schwartzman 2017). The case for a very warm Archean climate will be outlined shortly. These

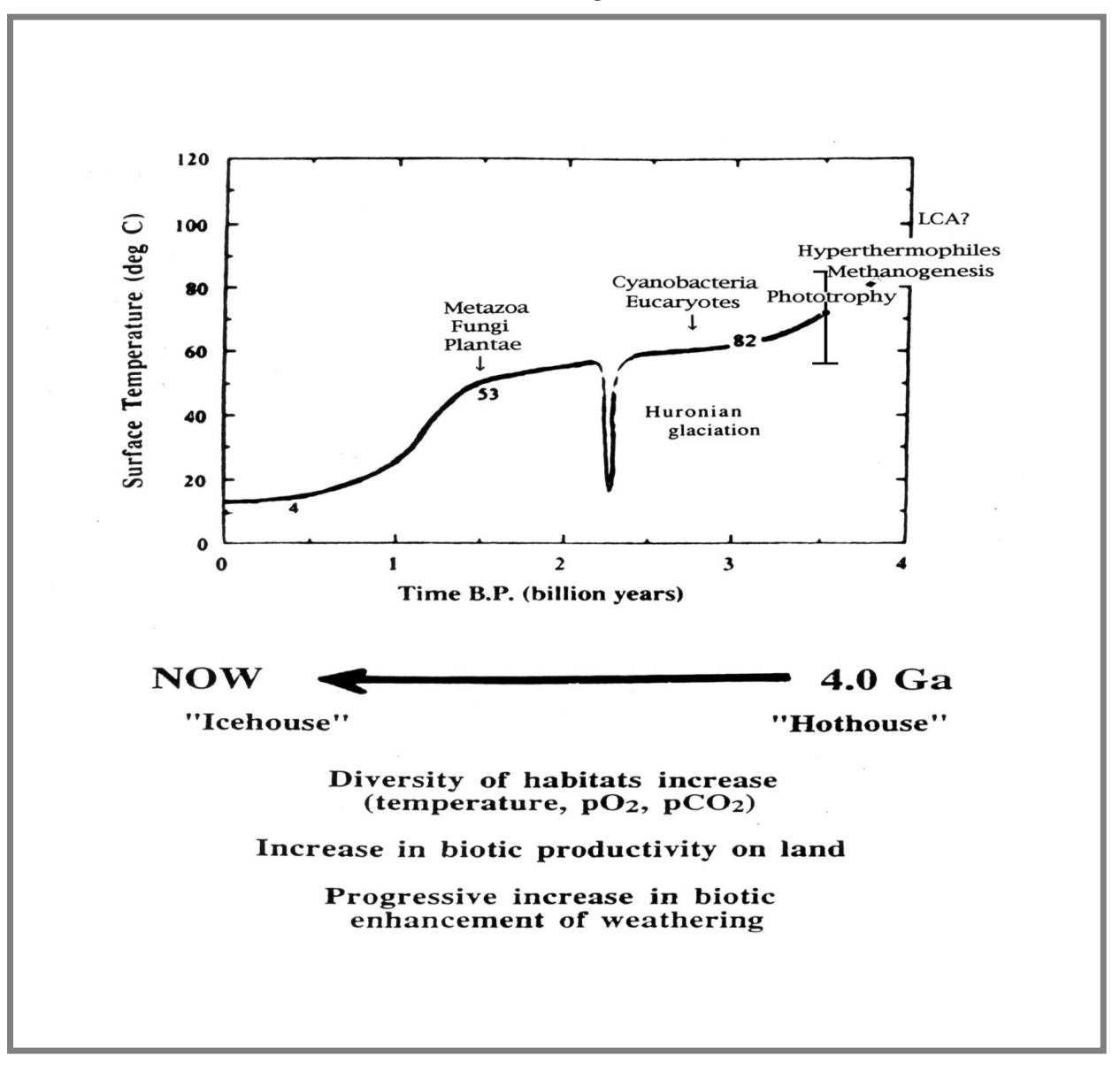

Figure 1. Temperature History of Biosphere

\begin{tabular}{|rll|}
\hline \multicolumn{2}{|c}{ Group } & \multicolumn{2}{c}{ Approximate upper } & Time of Emergence (Ga) \\
"Higher" kingdoms: & temperature limit $\left({ }^{\circ} \mathrm{C}\right)$ & \\
Plants & 50 & $0.5-1.5$ \\
Metazoans (Animals) & 50 & $0.6-1.5$ \\
Fungi & 60 & $0.6-2.4$ (?) \\
Eukaryotes & 60 & $2.1-2.8$ \\
Prokaryotes & & $>3.5$ \\
Phototrophs & 70 & $>3.8$ \\
Hyperthermophiles & $>100$ & \\
(Temperatures from Brock et al. 1994)
\end{tabular}

Table 1. Upper temperature limits for growth of living organisms, approximate times of their emergence emergences are illustrated in Figure 1 on the climatic temperature curve consistent with the hot early climate scenario, as well in Table 1.

The Earth's climate went from a "Hothouse" to an "Icehouse" in the last 4 billion years. The numbers on the curve correspond to the ratio of the present biotic enhancement of weathering to that at the indicated time in the 
past, as derived from modeling in Schwartzman (1999; 2002); see update in Schwartzman (2017). This curve leaves out Temperature excursions in the last billion years, including major glacial episodes.

The upper temperature limits are very likely primitive characters determined by the intrinsic biochemistry/

biophysics of cellular components, for example, the nuclear and mitochondrial membranes. Phototrophic organisms had over three billion years to adapt to hyperthermophilic temperatures (above $80^{\circ} \mathrm{C}$ ) but never succeeded; likewise during at least two billion years, eucaryotes did not succeed in adapting to temperatures above about $65^{\circ} \mathrm{C}$; there are no living hyperthermophilic phototrophs or eucaryotes. The empirical foundation for this temperature history is derived from the sedimentary chert oxygen isotopic record, specifically from the highest $\mathrm{O}^{18} / \mathrm{O}^{16}$ ratio at any age, as well as other evidence summarized as follows:

1) The oxygen isotope record in sedimentary chert and the compelling case for a near constant isotopic oxygen composition of seawater over geologic time support thermophilic surface temperatures prevailing in the Archean, with some support for hot conditions lasting until about 1.5 billion years ago, aside from lower temperatures during the glacial episodes at 2.2- 2.4 Ga and a problematic one at $2.9 \mathrm{Ga}$ (Pongola).

2) Melting temperatures of proteins resurrected from sequences inferred from robust molecular phylogenies give paleotemperatures at emergence consistent with a very warm early climate (see discussion below).

3) High atmospheric $\mathrm{pCO}_{2}$ levels in the Archean are consistent with high climatic temperatures near the triple point of primary iron minerals in banded iron formations and the formation of Mn-bicarbonate clusters leading to oxygenic photosynthesis.

4) Higher weathering intensities on land in the Archean would not have occurred if seafloor weathering dominated the carbon sink, pulling down the temperature; hence, this empirical evidence supports a hot climate and high carbon dioxide levels, likewise consistent with 50-6o bars of $\mathrm{CO}_{2}$ in the crust as carbonate and reduced organic carbon.

5) The inferred viscosity of seawater at $2.7 \mathrm{Ga}$ is consistent with a hot $\mathrm{Ar}$ chean climate.

6) A cold Archean is difficult to explain taking into account the higher outgassing rates of carbon dioxide, significantly smaller land areas and weaker biotic enhancement of weathering than present in the context of the long-term carbon cycle, taking into account the fainter Archean sun in climate modeling.

This case is discussed in more detail, including references with support for the arguments and evidence presented in the above list in Schwartzman, 2015; 2017; 2018.

\section{Critique of Recent Challenges to a Hot Archean Climate}

Re: Galili et al. (2019)

In their study of oxygen isotopic composition of marine iron oxides, they conclude that seawater has become isotopically lighter from the early Paleozoic to Archean time. However, their case rests on an inference of a non-uniformitarian variation in the seawater oxygen isotopic ratio for the sake of undermining a hot Archean climate. For a rebuttal of their interpretation of the chert Archean oxygen isotopic record see Knauth and Lowe (2003). Critically, their trend to lighter oxygen isotopic ratios of parent fluids for Fe oxides going back to $1.88 \mathrm{Ga}$ (their Fig. 2 D) is consistent with a meteoric water influence in diagenesis in the continental shelf or an estuarine environment (see, e.g., Fralick et al. 2017, noting that the oldest Fe oxides sampled by Galili et al. (2019) come from the Gibraltar Iron Formation, a Canadian deposit of the same age as the Gunflint Formation).

Further, they ignore the evidence for near present seawater $\mathrm{O}^{18} / \mathrm{O}^{16}$ ratio going back into the Archean including the following.

1) There are direct measurements of fossil seawater from salt inclusions for Paleozoic seawater (Knauth and Roberts 1991). The same conclusion comes from clumped isotope studies (Bergmann et al. 2017; Henkes et al. 2018; Ryb and Eiler 2018).

2) Likewise, the same conclusion comes from the inferred seawater ratio in the Neoproterozoic (76o Ma: Hodel et al. 2018) and Early Proterozoic (2.4 Ga: Zakharov and Bindeman 2019).

3) Again, the same conclusion is inferred from the geologic record of ancient seawater- altered oceanic crust (ophiolites, their ecologite proxies, greenstones). Aside from their problematic interpretation of this geologic record, Galili et al. (2019) fail to confront the evidence from Archean ecologite proxies for depleted/ enriched seawater-altered oceanic crust (Jacob 2004) with abundant depleted values, clear evidence of high temperature interaction with seawater, an $\mathrm{O}^{18}$ source for seawater during the buffering process, noting that a favorite way to generate lighter ratios has been to argue this process was not happening back in the early Precambrian. 
Re: Krissansen-Totton et al. (2018)

They model the long-term carbon cycle, concluding that current best knowledge of this cycle precludes a hot Archean. However, rather than actually critiquing the robust empirical case for a hot Archean climate they cite, they make a model to refute it by generating a Sleep and Zahnle (2001) model with sufficient seafloor weathering to keep Archean temperatures below 50 deg $\mathrm{C}$. Ignored is evidence for high Hadean/Archean $\mathrm{pCO}_{2}$ levels in the atmosphere/ocean as well as higher weathering intensities on land.

\section{Re: Charnay et al. (2017)}

From their $3 \mathrm{D}$ climate-carbon model, they "favor cold or temperate climates with global mean temperatures between around $8^{\circ} \mathrm{C}(281 \mathrm{~K})$ and $30^{\circ} \mathrm{C}$ $(303 \mathrm{~K})$ and with $0.1-0.36$ bar of $\mathrm{CO}_{2}$ for the late Hadean and early Archean." However, the much lower biotic enhancement of weathering on land in this early time was not included in their modeling of the long-term carbon cycle; further, the recycling of $\mathrm{CO}_{2}$ back in subduction zones in Archean was likely close to $100 \%$ efficient because of a hotter upper mantle rather than the lower value they assume.

\section{Temperature History from Molecu- lar Phylogeny}

More evidence for this temperature history comes from molecular phylogeny of organisms belonging to the three main domains of life, Bacteria, Archaea and Eukarya, noting the apparent absence on the rRNA phylogenetic tree of deeply-rooted mesophiles/

psychrophiles (see, e.g., Figure 1 in Schwartzman and Lineweaver 2004). If Archean temperatures were similar to the Phanerozoic, then some of the lowtemperature prokaryotes should be grouped near the root with the hyperthermophiles/thermophiles. While some more recent phylogenetic trees are more ambiguous regarding this conclusion (e.g., see Lineweaver and Chopra 2019 citing Hug et al. 2016), Weiss et al.'s (2016a) research supports a thermophilic LUCA:

The concept of a last universal common ancestor of all cells (LUCA, or the progenote) is central to the study of early evolution and life's origin, yet information about how and where LUCA lived is lacking. We investigated all clusters and phylogenetic trees for 6.1 million protein coding genes from sequenced prokaryotic genomes in order to reconstruct the microbial ecology of LUCA. Among 286,514 protein clusters, we identified 355 protein families (o.1\%) that trace to LUCA by phylogenetic criteria. Because these proteins are not universally distributed, they can shed light on LUCA's physiology. Their functions, properties and prosthetic groups depict LUCA as anaerobic, $\mathrm{CO}_{2}$-fixing, $\mathrm{H}_{2}$ dependent with a Wood-Ljungdahl pathway, $\mathrm{N}_{2}$-fixing and thermophilic. LUCA's biochemistry was replete with FeS clusters and radical reaction mechanisms... . The 355 phylogenies identify clostridia and methanogens, whose modern lifestyles resemble that of LUCA, as basal among their respective domains. LUCA inhabited a geochemically active environment rich in $\mathrm{H}_{2}$, $\mathrm{CO}_{2}$ and iron. The data support the theory of an autotrophic origin of life involving the Wood-Ljungdahl pathway in a hydrothermal setting." (Abstract)

For more views on the concept of LUCA and its identification, see, for example, the following papers: Gogarten and Deamer (2016) with a reply by Weiss et al. (2016b), Di Giulio (2019) and Lineweaver (in press).
The inferred paleotemperatures from resurrected (elongation) proteins of cyanobacteria are consistent with a hot Archean climate, with cyanobacteria emerging at about $60^{\circ} \mathrm{C}$ at $2.8 \mathrm{Ga}$. (Garcia et al. 2017, as proposed by Schwartzman et al. 2008 and Gaucher et al. 2008; also see Fournier and Alm 2015; Romero-Romero et al. 2016; Boussau et al. 2008).

\section{The Burst of Encephalization in the} Late Cenozoic

For warm-blooded animals, the body temperature $\mathrm{T}_{\text {body }}$ is close to the upper limit of $4 \mathrm{O}^{\circ} \mathrm{C}$ for vertebrates, thereby providing for the energy-intensive brain while the differential between body and climatic temperature, $\mathrm{T}_{\text {body }}-\mathrm{T}_{\text {climate }}$, determines the efficiency of heat loss from brain, recognizing that humidity and the evolution of sweating and hair distribution on the body also impact heat loss. Hence, we have proposed that climatic cooling is a prime releaser for encephalization (Schwartzman et al. 2009), with the window of opportunity for maximum encephalization shown in Figure 2. Thus, I argue that an intelligence niche, among other solutions to reproductive survival, exists on our planet and by implication potentially on other Earth-like planets around Sunlike stars. On Earth we have an intelligence niche for lineages in birds

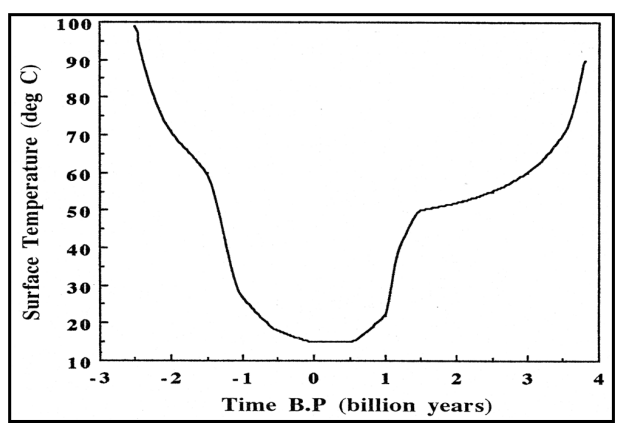

Figure 2. The surface temperature of the Earth in the past and projected for the future (positive and negative respectively on the $x-$ axis), noting that 0 is the present and the temperature curve of the past approximates and compresses what is seen in Figure 1. A window for maximum encephalization is generated between +1 and -1 billion years B.P. 
Schwartzman, Biospheric Evolution

(e.g., corvids), marine mammals (e.g., dolphins) and terrestrial mammals (e.g., elephants, anthropoid apes, hominins) in the Cenozoic. Dunbar's (2016) strong case for sociality driving the evolution of big brains in mammals is the context for climate cooling reducing the constraint of inefficient heat loss from bigger brains. Thus, social animals are an apparent attractor niche for encephalization, and for warm blooded animals heat loss from an energyintensive brain is a constraint. For primates in particular, Street et al. (2017) have made a convincing case that brain expansion and high reliance on culturally transmitted behavior coevolved with sociality and extended lifespan.

\section{Conclusion}

The case outlined here points to an important conclusion regarding biological evolution, namely,

to the critical role of a temperature constraint holding back the emergence of major organismal groups, starting with phototrophs in the Archean, culminating with eucaryotes, then metazoans in the Proterozoic and the burst of encephalization in the late Cenozoic. (It is important also to acknowledge that the constraints on biotic evolution have included atmospheric oxygen levels on macroeucaryotes, including metazoans in the Phanerozoic, along with atmospheric carbon dioxide levels on emergence of lichens and leaves (megaphylls) in the Devonian).

The pattern of biospheric evolution argued here raises the potential of similar coevolutionary relationships of life and its environment on Earth-like planets around Sun-like stars.

\section{Acknowledgements}

This paper expands on my presentation to the International Symposium on Life in the Universe 2019, Big History, SETI and the Future of Humankind, Milan (Milano), Italy, given on

July 15, 2019 (https://bighistory.org/setiand-big-history). I thank the audience for their questions, as well as Tyler Volk for our long continuing discussions on this subject and Charley Lineweaver for critical comments in a reading of the draft of this paper.

\section{References}

Bergmann, K., S. Finnegan, R. Creel, et al. 2017. "A Paired Apatite and Calcite Clumped Isotope Thermometry Approach to Estimating CambroOrdovician Seawater Temperatures and Isotopic Composition." Geochimica et Cosmochimica Acta 224: 18 -41 .

Blount, Z. D. 2017. "Replaying Evolution." American Scientist 105 (3): 156165 .

Blount, Z. D., R. E. Lenski, and J. B. Losos. 2018. "Contingency and Determinism in Evolution: Replaying Life's Tape." Science 362 (6415), doi: 10.1126/ science.aam5979.

Boussau, B., S. Blanquart, A. Necsulea, N. Lartillot, and M. Gouy. 2008. "Parallel Adaptations to High Temperatures in the Archaean Eon. $\mathrm{Na}$ ture 456: 942-945.

Brock, T. D., M. T. Madigan, J. M. Martinko, and J. Parker. 1994. Biology of Microorganisms. 7th ed. Englewood Cliffs, NJ: Prentice Hall.

Caldeira, K., and J. F. Kasting. 1992. "The Life Span of the Biosphere Revisited." Nature 360: 721-723.

Camprubi, E., S. F. Jordan, R. Vasiliadou, et al. 2017. "Iron Catalysis at the Origin of Life.” IUBMB Life 69(6):373381.

Chaisson, E. J. 2009. "Exobiology and Complexity." In: R. Myers, ed. Encyclopedia of Complexity and Systems
Science. Berlin: Springer, 3267- 3284.

Charnay, B, G. Le Hir, F. Fluteau, F. Forget, and D. C. Catling. 2017. "A Warm or a Cold Early Earth? New Insights from a 3-D Climate-carbon Model." Earth and Planetary Science Letters 474: 97-109.

Conway Morris, S. 2003. Life's Solution: Inevitable Humans in a Lonely Universe. Cambridge: Cambridge University Press.

Conway Morris, S. 2010. "Evolution: Like Any Other Science It Is Predictable." Philosophical Transactions of the Royal Society B: Biological Sciences: 365, 133-145. doi:10.1098/ rstb.2009.0154.

Conway Morris, S. 2015. The Runes of Evolution: How the Universe Became Self-Aware. West Conshohocken: Templeton Press.

Conway Morris, S and S. J. Gould. 19981999. "Showdown on the Burgess Shale." Natural History 107 (10): 4855 .

Di Giulio, M. 2019. The Universal Ancestor, the Deeper Nodes of the Tree of Life, and the Fundamental Types of Primary Cells (Cellular Domains)." Journal of Theoretical Biology 460: 142 $-143$.

Dunbar, R. 2016. Human Evolution. Oxford UK: Oxford University Press.

Fournier, G. P., and E. J. Alm. 2015. "Ancestral Reconstruction of a PreLUCA Aminoacyl-tRNA Synthetase Ancestor Supports the Late Addition of Trp to the Genetic Code." Journal of Molecular Evolution. doi:10.1007/ soo239-015-9672-1.

Fralick, P., N. Planavsky, J. Burton, et al. 2017. "Geochemistry of Paleoproterozoic Gunflint Formation Carbonate: Implications for Hydrosphere- 
atmosphere Evolution.” Precambrian Research 290: 126-146.

Galili, N., A. Shemesh, R. Yam, et al. 2019. "The Geologic History of Seawater Oxygen Isotopes from Marine Iron Oxides." Science 365 (6452): 469-473.

Garcia, A. K., J.W. Schopf, S-i Yokobori, et al. 2017. "Reconstructed Ancestral Enzymes Suggest Long-term Cooling of Earth's Photic Zone since the Archean." Proceedings of the National Academy of Sciences of the United States of America 114: 4619-4624.

Gaucher, E.A., S. Govindaraja, and O. K. Ganesh. 20o8. "Palaeotemperature Trend for Precambrian Life Inferred from Resurrected Proteins.” Nature 451, 704-708.

Gogarten, J. P., and D. Deamer. 2016. "Is LUCA a Thermophilic Progenote?" Nature Microbiology 1: 16229. doi: 10.1038/NMICROBIOL.2016.229.

Henkes, G. A., B. H. Passey, E. L. Grossman, et al. 2018. "Temperature Evolution and the Oxygen Isotope Composition? of Phanerozoic Oceans from Carbonate Clumped Isotope Thermometry." Earth and Planetary Science Letters 490: 4050.

Hodel, F., M. Macouin, R.I. F. Trindade, et al. 2018. "Fossil Black Smoker Yields Oxygen Isotopic Composition of Neoproterozoic Seawater.” Nature Communications 9:1453. doi: 10.1038/s41467-018-03890-w.

Hug, L., B. J. Baker, K. Anantharaman, et al. 2016. "A New View of the Tree of Life." Nature Microbiology 1: 16048 .

Jacob, D. E. 2004. "Nature and Origin of Eclogite Xenoliths from Kimberlites." Lithos 77: 295-316.
Knauth, L.P., and D. R. Lowe. 2003. "High Archean Climatic Temperature Inferred from Oxygen Isotope Geochemistry of Cherts in the 3.5 Ga Swaziland Supergroup, South Africa." Geological Society of America Bulletin 115 (5): 566-580.

Knauth, L. P., and S. K. Roberts. 1991 "The Hydrogen and Oxygen Isotopic History of the Silurian- Permian Hydrosphere as Determined by Direct Measurement of Fossil Water." Geochemical Society Special Publication No. 3: 91-104.

Krissansen-Totton, J, G. N. Arney, and D. C. Catling. 2018. "Constraining the Climate and Ocean $\mathrm{pH}$ of the Early Earth with a Geological Carbon Cycle Model." Proceedings of the National Academy of Sciences of the United States of America 115 (16): 4105-4110.

Lane, N. 2015. The Vital Question: Energy, Evolution and the Origins of Complex Life. New York: W. W. Norton.

Lenton, T. M., S. J. Daines, J. G. Dyke, A. E. Nicholson, D. M. Wilkinson, and H. T. P. Williams. 2018. "Selection for Gaia across Multiple Scales." Trends in Ecology E Evolution 33: 633-645.

Li, Y., N. Kitadai, and R. Nakamura. 2018. "Chemical Diversity of Metal Sulfide Minerals and Its Implications for the Origin of Life." Life 8: 46; doi:10.339o/life8040046.

Lineweaver, C. H. In press. "What Do the DPANN Archaea and the CPR Bacteria Tell Us about the Last Universal Common Ancestors?" In: Seckbach J. and H. Stan-Lotter (eds) Extrememophiles as Astrobiological Models. Beverly, MA: Scrivener-Wiley.
Lineweaver, C. H., and A. Chopra. 2019. "The Biological Overview Effect: Our Place in Nature." Journal of Big History III (3): 109-122.

Lineweaver, C. H., and D. Schwartzman. 2004. "Cosmic Thermobiology, Thermal Constraints on the Origin and Evolution of Life." In: Seckbach, J. (ed) Origins: Genesis, Evolution and Biodiversity of Microbial Life in the Universe. Dordrecht: Kluwer Academic Publishers, 233248.

Martin, W., and M. J. Russell. 2007. “On the Origin of Biochemistry at an Alkaline Hydrothermal Vent.” Philosophical Transactions of the Royal Society B: Biological Sciences 362: 1887-925.

Nicholson, A. E., D. M. Wilkinson, H. T. P. Williams, and T. M. Lenton. 2018. “Alternative Mechanisms for Gaia." Journal of Theoretical Biology 457: 249-257.

Pace, N. R. 1997. “A Molecular View of Microbial Diversity and the Biosphere." Science 276: 734-740.

Romero-Romero, M. L., V. A. Risso, S. Martinez-Rodriguez, E. A. Gaucher, et al. 2016. "Selection for Protein Kinetic Stability Connects Denaturation Temperatures to Organismal Temperatures and Provides Clues to Archaean Life.” PLoS ONE 11(6): eo156657.

Russell, M. J., and A. J. Hall. 1997. “The Emergence of Life from Iron Monosulphide Bubbles at a Submarine Hydrothermal Redox and $\mathrm{pH}$ Front." Journal of the Geological. Society, London 154, 377-402.

Ryb, U., and J. M. Eiler. 2018. “Oxygen Isotope Composition of the Phanerozoic Ocean and a Possible Solution to the Dolomite Problem." Proceedings of the National Academy of 
Sciences of the United States of

America 115 (26): 6602-6607.

Schwartzman, D. 1999, 2002. Life, Temperature, and the Earth: The SelfOrganizing Biosphere. New York: Columbia University Press.

Schwartzman, D. 2001. "Playing the Tape Again, a Deterministic Theory of Biosphere/Biotic Evolution." In: Earth System Science:A New Subject for Study (Geophysiology) or a New Philosophy? International School Earth and Planetary Sciences, Proceedings (S. Guerzoni, S. Harding, T. Lenton and F. Ricci Lucchi, eds.), Schwartzman, D. W., and C. H. LinSiena 2001, 53-60.

Schwartzman, D. 2015. "The Case for a Hot Archean Climate and Its Implications to the History of the Biosphere." Arxiv.org., April 1.

Schwartzman, D. 2017. “Life's Critical Role in the Long-term Carbon $\mathrm{Cy}$ cle: the Biotic Enhancement of Weathering." AIMS Geosciences 3 (2): $216-238$.

Schwartzman, D. 2018. "The Dialectics of Biospheric Evolution." In Awerbuch, Tamara, Maynard S. Clark, and Peter J. Taylor, eds. The Truth is the Whole: Essays in Honor of Richard Levins. Arlington, MA: The Pumping Station, 21-33.

Schwartzman D, K. Caldeira, and A. Pavlov. 2008."Cyanobacterial Emergence at 2.8 Gya and Greenhouse Feedbacks." Astrobiology 8 (1): 187203.

Schwartzman, D., and C. H. Lineweaver. 2005. "Temperature, Biogenesis and Biospheric Self-Organization." In: Kleidon, A., and R. D. Lorenz, eds. Non-Equilibrium Thermodynamics and the Production of Entropy: Life, Earth, and Beyond. Berlin: Springer, Chapter 16, 207-221.
Schwartzman. D., G. Middendorf, and M. Armour-Chelu. 2009. "Was Climate the Prime Releaser for Encephalization?" Climatic Change 95 (3): 439-447.

Schwartzman. D. W., and L. P. Knauth. 2009. "A Hot Climate on Early Earth: Implications to Biospheric Evolution. In: Meech K. J. et al., eds. Bioastronomy 2007: Molecules, Microbes, and Extraterrestrial Life 420 , 221-228, Astronomical Society of the Pacific Conference Series, San Francisco. eweaver. 2004. "The Hyperthermophilic Origin of Life Revisited." Biochemical. Society Transactions 32: 168-171.

Simoes, T. R. 2019. "Contingency vs. Predictability in Evolution." Nature Research: Ecology and Evolution. https://

natureecoevocommunity.nature.com/users/87830-tiago-rsimoes/posts/43332-contingency-vs -predictability-in-evolution.

Sleep, N. H., and K. Zahnle. 2001.

"Carbon Dioxide Cycling and Implications for Climate on Ancient Earth." Journal of Geophysical Research: Planets 106: 1373-1399.

Sojo, V., B. Herschy, A. Whicher, et al. 2016. "The Origin of Life in Alkaline Hydrothermal Vents." Astrobiology 16 (2): 181-197.

Street, S. E., A. F. Navarrete, S. M. Reader, et al. 2017. "Coevolution of Cultural Intelligence, Extended Life History, Sociality, and Brain Size in Primates." Proceedings of the National Academy of Sciences of the United States of America 114 (30): 7908-7914.
Weiss, M. C., S. Neukirchen, M. Roettger, et al. 2016b. Reply to "Is LUCA a Thermophilic Progenote?" Nature Microbiology 1: 16230. doi: 10.1038/ NMICROBIOL.2016.230.

Weiss, M. C., F. L. Sousa, N. Mrnjavac, et al. 2016a. "The Physiology and Habitat of the Last Universal Common Ancestor. Nature Microbiology 1: 16116. doi: 10.1038/ NMICROBIOL.2016.116.

Zakharov, D. O., and I. N. Bindeman. 2019. "Triple Oxygen and Hydrogen Isotopic Study of Hydrothermally Altered Rocks from the 2.43-2.41 Ga Vetreny Belt, Russia: An Insight into the Early Paleoproterozoic Seawater." Geochimica et Cosmochimica Acta 248: 185-209. 